\title{
Towards methodology and metrics for assessing lumbar exoskeletons in industrial applications
}

\author{
Lorenzo Grazi \\ The BioRobotics Institute \\ Scuola Superiore Sant'Anna \\ Pisa, Italy \\ lorenzo.grazi@santannapisa.it \\ Nicola Vitiello \\ The BioRobotics Institute \\ Scuola Superiore Sant'Anna \\ Pisa, Italy \\ Fondazione Don Carlo Gnocchi \\ Firenze, Italy \\ nicola.vitiello@santannapisa.it
}

\author{
Baojun Chen \\ The BioRobotics Institute \\ Scuola Superiore Sant'Anna \\ Pisa, Italy \\ baojun.chen@santannapisa.it \\ Simona Crea \\ The BioRobotics Institute \\ Scuola Superiore Sant'Anna \\ Pisa, Italy \\ Fondazione Don Carlo Gnocchi \\ Firenze, Italy \\ simona.crea@santannapisa.it
}

\author{
Francesco Lanotte \\ The BioRobotics Institute \\ Scuola Superiore Sant'Anna \\ Pisa, Italy \\ francesco.lanotte@santannapisa.it
}

\begin{abstract}
Lumbar exoskeletons have the potential to reduce work-related musculoskeletal disorders and injuries in workers performing repetitive manual handling tasks. For a wide adoption of exoskeletons in industrial workplaces the definition of methodologies and metrics is crucial. In this paper, we present an overview of evaluation methods and metrics from state-of-the-art studies and propose a set of suitable evaluation tests and metrics to evaluate lumbar exoskeletons.
\end{abstract}

Keywords - Exoskeletons, benchmarking, industry 4.0, metrics

\section{INTRODUCTION}

Work-related musculoskeletal disorders (WMSDs) in the low-back still affect a considerable number of workers in modern factories. Indeed, although automation is widespread in industrial workplaces, workers are still required to perform physically demanding tasks, such as manual handling of heavy goods in manufacturing and logistics [1]. In this case, workers are typically exposed to physical risks for prolonged periods within a shift of repetitive lifting, trunk bending and twisting [2]. Consequently, occurrence prevention and incidence reduction of low-back WMSDs (e.g. low-back pain) have been widely investigated [3]-[6]. Different strategies have shown positive effects to reduce low-back pain in manual handling tasks, such as training of workers about the correct techniques to handle heavy loads [5], fostering the use of weight-relief mechanical devices [2] or wearable such as lumbar supports [7] and insoles [8] or optimizing the workplace by adopting job rotations [9]. Despite the huge effort of majority of factories in the implementation of these measures towards the improvement of workplaces, the incidence of low-back pain is still considerably high, as it affects a considerable percentage of the workforce in western countries [1], [10], [11].

In the last decade, many researchers have been considering exoskeletons as a new technological tool for tackling the occurrence of WMSDs by assisting workers in performing repetitive and even strenuous jobs [12]. An exoskeleton is a wearable device that augments, restores or empowers human movement functions and performance. Exoskeletons can be categorized into passive and active devices, depending on whether they have powered actuators or not. Despite the huge potential of this technology, a consensus on the methods and metrics for the evaluation of exoskeletons for worker assistance has not been reached yet and it would be important to compare different prototypes and foster the diffusion of this technology in manufacturing plants.

In this paper, we present an overview of the methodologies used in previous experiments carried out with healthy participants performing repetitive lifting tasks with an active lower-limb exoskeleton [13]-[16]. Moreover, we propose a set of suitable metrics that can be used to evaluate and compare lumbar exoskeletons.

The goal of this work is to foster the discussion on the need for common evaluation methodologies and metrics that can serve as guidelines for lumbar industrial exoskeletons evaluation.

\section{STATE OF ART}

Table I and Table II provide an overview of the methods and metrics from studies carried out with exoskeletons assisting the load lifting task. Reported examples include studies with active [13], [17], [18] and passive [19], [20] exoskeletons.

\section{PROPOSED METHOD AND METRICS}

\section{A. Experimental conditions}

In state-of-the-art experiments, the lifting trials have been designed to replicate a scenario of repetitive load lifting, similar to the one presented in [13]. In our previous studies, we used the APO, a powered robotic hip exoskeleton, designed to assist the hip flexion-extension movement [13]-[16]. Recruited subjects were asked to repetitively perform lifting and lowering of a $5-\mathrm{kg}$ box between two locations at different heights.

A prototypical experiment with an exoskeleton for lumbar support is composed of three trials, each corresponding to a different tested condition (randomized across subjects):

- NO EXO: subjects are asked to lift a pre-defined load without wearing the exoskeleton; 
TABLE I. OVERVIEW OF EXPERIMENTAL DESIGNS FOR A SAMPLE OF REPRESENTATIVE STUDIES

\begin{tabular}{|c|c|c|c|c|c|}
\hline Device & Task type & Tested conditions & Weight & $\begin{array}{c}\text { Number of movements } \\
\text { per condition } \\
\text { (cadence) }\end{array}$ & Number of subjects \\
\hline $\mathrm{APO}[13]$ & Symmetric freestyle & $\begin{array}{l}\text { EXO TM, EXO AM } \\
\text { (randomized) }\end{array}$ & $10 \mathrm{~kg}$ & 30 (5 lifts/min) & 5 (male) \\
\hline Robo-Mate [17] & not available & $\begin{array}{l}\text { NO EXO (2 times), } \\
\text { EXO (2 times) } \\
\text { (randomized) }\end{array}$ & $7.5,15 \mathrm{~kg}$ & $\begin{array}{l}5 \text { (cadence not } \\
\text { available) }\end{array}$ & 12 (male) \\
\hline $\begin{array}{l}\text { HAL for care support } \\
{[18]}\end{array}$ & Symmetric freestyle & NO EXO, EXO & $17.05 \mathrm{~kg}$ & 40 (4 lifts/min) & 14 (male) \\
\hline PLAD-1 [19] & $\begin{array}{l}\text { Asymmetric freestyle, } \\
\text { stoop, squat }\end{array}$ & $\begin{array}{l}\text { NO EXO, EXO } \\
\text { (randomized) }\end{array}$ & $5,15,25 \mathrm{~kg}$ & $\begin{array}{l}54 \text { (cadence not } \\
\text { available) } \\
\text { (one lift per } \\
\text { combination of task } \\
\text { type and tested } \\
\text { condition) }\end{array}$ & 9 (male) \\
\hline PLAD-2 [20] & Symmetric freestyle & $\begin{array}{l}\text { NO EXO, EXO } \\
\text { (randomized) } \\
\text { (each condition } \\
\text { occurred seven days } \\
\text { apart) }\end{array}$ & Weight not available & 540 (6 lifts/min) & 10 (male) \\
\hline
\end{tabular}

- EXO TM: subjects are required to lift the load wearing the exoskeleton, which is controlled to provide null output torque;

- EXO AM: subjects are required to lift the load wearing the exoskeleton which provides an assistive action during the trunk extension phase.

These three conditions are designed to allow the following comparisons:

- EXO TM vs NO EXO: to evaluate the effect of wearing the exoskeleton on the user;

- EXO AM vs NO EXO: to evaluate the overall effect of the exoskeleton and the assistive action;

- EXO AM vs EXO TM: it can be useful to evaluate only the effect of the assistance, without taking into consideration the potential loading effect of the exoskeleton.

\section{B. Evaluation metrics}

Five categories of metrics have been found useful to evaluate the exoskeleton in the experimental application: human biomechanics, electromyography, physiological parameters, exoskeleton-related parameters and subjective questionnaires.

\section{1) Human biomechanics}

Movement analysis is commonly done in human biomechanics research and clinical investigation to compute the joints kinematics and dynamics.

The joint kinematics is usually computed by dedicated software that use the $3 \mathrm{D}$ reconstruction of markers placed on anatomic landmarks and tracked by cameras. Moreover, joint torques can be computed by inverse dynamics using the ground reaction force measured by force platforms.

The analysis of human biomechanics can provide useful information for evaluating the effect of an exoskeleton on the human body. Indeed, the result of motion analysis can highlight whether the use of the exoskeleton affects the kinematics of the wearer, for example modifying the range of movement (RoM) while performing the task [21]. Additionally, it is also important to quantify whether wearing the exoskeleton has any loading effects on the human posture: indeed, as a consequence of the mass distribution of the exoskeleton, the wearer may put in place compensatory abnormal muscles activations, which can be reflected by kinematics modifications.

The time to perform the task is also an important metric that can be affected by the assistive action of the exoskeleton and it can be measured through the joint angle profiles.

\section{2) Electromyography}

Electromyography (EMG) analysis can be used to investigate superficial muscular activity. Regardless of the application, EMG analysis is a common practice in exoskeleton assessment [13], [17], [21]-[24]. Indeed, thanks to the measurement of EMG signals, the effects of using an exoskeleton on specific muscular groups can be investigated. Typically, the expected outcome of this analysis is the reduction of the muscular activity and fatigue in muscle groups which contribute primarily to perform the working task and that are assisted by the exoskeleton (e.g. back muscles in the case of load lifting, such as Lumbar Erector Spinae and Thoracic Erector Spinae) [12]. On the other hand, the EMG analysis can also highlight potential undesired effects on muscle groups that are not assisted by the exoskeleton (e.g. abnormal/increased muscles activity to counteract the mass of the exoskeleton and its distribution, such as Rectus Femoris or Tibialis Anterior) [12].

EMG analysis can be performed in the time or the frequency domain. Time-domain analysis is computed on the raw acquired signals and typically involves the extraction of the signal linear envelope, activation peak, integral, and root mean square. The frequency-domain metrics refer to the analysis of the changes in the frequency content of raw signals, as mean and median frequency of the power spectrum, whose shift towards low frequency is an index of muscle fatigue occurrence [25]. 
TABLE II. OVERVIEW OF THE METRICS USED IN THE SELECTED STUDIES

\begin{tabular}{|c|c|c|c|c|c|c|}
\hline Device & $\begin{array}{c}\text { Human } \\
\text { biomechanics }\end{array}$ & Electromyography & $\begin{array}{c}\text { Physiological } \\
\text { parameters }\end{array}$ & Exoskeleton data & Questionnaires & Others \\
\hline APO [13] & not available & $\begin{array}{l}\text { Lumbar Erector Spinae, } \\
\text { Thoracic Erector Spinae, } \\
\text { Erector Spinae Iliocostalis, } \\
\text { Rectus Femoris, Biceps } \\
\text { Femoris (unilaterally) }\end{array}$ & not available & $\begin{array}{l}\text { Hip joint } \\
\text { kinematics, hip } \\
\text { joint torque, } \\
\text { trunk extension } \\
\text { time }\end{array}$ & not available & not available \\
\hline Robo-Mate [17] & not available & $\begin{array}{l}\text { Lumbar Erector Spinae, } \\
\text { Rectus Abdominalis, Biceps } \\
\text { Femoris (unilaterally) }\end{array}$ & not available & not available & $\begin{array}{l}\text { Borg CR10, } \\
\text { Local Perceived } \\
\text { Pressure, SUS }\end{array}$ & $\begin{array}{l}\text { Contact pressure } \\
\text { at the physical } \\
\text { interface }\end{array}$ \\
\hline $\begin{array}{l}\text { HAL for care } \\
\text { support [18] }\end{array}$ & not available & $\begin{array}{l}\text { Lumbar Erector Spinae, } \\
\text { Thoracic Erector Spinae, } \\
\text { Quadriceps Femoris } \\
\text { (bilaterally) }\end{array}$ & Heart rate & not available & Borg RPE & not available \\
\hline PLAD-1 [19] & $\begin{array}{l}\text { Trunk } \\
\text { moments }\end{array}$ & $\begin{array}{l}\text { Lumbar Erector Spinae, } \\
\text { Thoracic Erector Spinae, } \\
\text { External Obliques, Rectus } \\
\text { Abdominalis }\end{array}$ & not available & not available & $\begin{array}{l}\text { Comfort, } \\
\text { effectiveness } \\
\text { (ad-hoc) }\end{array}$ & not available \\
\hline PLAD-2 [20] & not available & $\begin{array}{l}\text { Lumbar Erector Spinae, } \\
\text { Thoracic Erector Spinae }\end{array}$ & Heart rate & not available & Borg RPE & $\begin{array}{l}\text { Maximum back } \\
\text { extensor muscles } \\
\text { strength, } \\
\text { endurance time }\end{array}$ \\
\hline
\end{tabular}

\section{3) Physiological parameters}

Physiological parameters, such as heart rate (HR), breath frequency, skin temperature and galvanic skin response, are indicators of global fatigue. Differently from EMG, these parameters reflect systemic changes that arise in the human body and are controlled by the autonomic nervous system. For the assessment of an exoskeleton, they can highlight if its use positively or negatively influences wearer's physiological responses, namely if it reduces or increases the overall fatigue status. For example, the increase of the HR indicates an increased demand for body oxygen, thus giving information on the physical effort done by users. Similarly, the increase of the skin conductance level (i.e. the tonic component of galvanic skin response) also can reflect an increase of the physical exertion [26].

\section{4) Exoskeleton-related parameters}

Sensors integrated in the exoskeleton can provide data related to the kinematics of the exoskeleton joints and assistance. Kinematics of the exoskeleton can be compared with the kinematics obtained from motion capture, to compute differences between them and possible relative movements between the exoskeleton and the human body, leading to misalignments that can cause undesired forces and overloads to human articulations [27].

Data related to the assistance delivered by the exoskeleton, such as torque and power, can give additional relevant information, such as the similarity between exoskeleton torque and human joint moments, or the ratio between positive and negative mechanical power. This latter information can be very useful in understanding if the designed assistive action of the exoskeleton is compatible with human biomechanics.

\section{5) Subjective questionnaires}

Administering questionnaires can provide information about the subjective perception of the exoskeleton, in terms of comfort, ease of use and effectiveness. They require little time to be carried out and, in most cases, namely when wellvalidated questionnaires are used, offer reliable results. Typically used questionnaires are the system usability scale (SUS) [28], the NASA-TLX [29], and the Borg scales [30], but also not-standard and ad-hoc surveys can be administered.

\section{Performance indices}

Based on the evaluation categories presented, in this section we summarized the performance indices that can be considered more relevant for the assessment of lumbar exoskeletons in industrial applications:

- RoM: it allows to assess if the use of an exoskeleton would limit the maximum range of movement allowed to the user. Ideally, an exoskeleton should ensure all physiological movements, without hindering them.

- Time to extend the trunk: it allows the evaluation of how the use of an exoskeleton can affect the lifting movement in terms of the time needed to lift an object. In other terms, it is related to the speed of the lifting action.

- Peak value, root mean square and integral of the EMG linear envelope: they highlight the level of muscles activation. They can be also reported as percentage of the maximum voluntary contraction to allow inter-subject comparison.

- Mean and median frequency of the EMG spectrum: the frequency content of the EMG signal can be used to extract information about the level of muscular fatigue in prolonged tasks.

- HR: it provides information about the global fatigue experienced by users. Measuring this parameter and its variability can be useful to understand if, for example, simply wearing an exoskeleton increases the global workload. 
TABLE III. RESULTS OF EMG ANALYSIS FROM SELECTED STUDIES

\begin{tabular}{|c|c|c|c|c|}
\hline Device & Measured muscles & Performance metric & Evaluation method & Results \\
\hline APO [13] & $\begin{array}{l}\text { Lumbar Erector Spinae, } \\
\text { Thoracic Erector Spinae, } \\
\text { Erector Spinae } \\
\text { Iliocostalis, Rectus } \\
\text { Femoris, Biceps Femoris } \\
\text { (unilaterally) }\end{array}$ & EMG integral & $\begin{array}{l}\text { Comparison } \\
\text { between TM and } \\
\text { AM, with and } \\
\text { without holding the } \\
\text { load }\end{array}$ & $\begin{array}{l}\text { Lumbar Erector Spinae: }-15.9 \% \text { (with load), }-33 \% \\
\text { (without load) } \\
\text { Thoracic Erector Spinae: }-6 \% \text { (with load), }-10.1 \% \\
\text { (without load) } \\
\text { Erector Spinae Iliocostalis: }-3.6 \% \text { (with load), - } \\
8.9 \% \text { (without load) } \\
\text { Rectus Femoris: }+33.7 \% \text { (with load), }+40.1 \% \\
\text { (without load) } \\
\text { Biceps Femoris: }-27.4 \% \text { (with load), }+7.1 \% \\
\text { (without load) }\end{array}$ \\
\hline Robo-Mate [17] & $\begin{array}{l}\text { Lumbar Erector Spinae, } \\
\text { Rectus Abdominalis, } \\
\text { Biceps Femoris } \\
\text { (unilaterally) }\end{array}$ & $\begin{array}{l}\text { EMG root mean } \\
\text { square }\end{array}$ & $\begin{array}{l}\text { Comparison } \\
\text { between without } \\
\text { and with the } \\
\text { exoskeleton (with } \\
\text { different weights) }\end{array}$ & $\begin{array}{l}\text { Lumbar Erector Spinae: }-12 \%(7.5 \mathrm{~kg}),-15 \% \text { (15 } \\
\mathrm{kg}) \\
\text { Biceps Femoris: }-5 \%(7.5 \mathrm{~kg}),+5 \%(15 \mathrm{~kg})\end{array}$ \\
\hline $\begin{array}{l}\text { HAL for care } \\
\text { support [18] }\end{array}$ & $\begin{array}{l}\text { Lumbar Erector Spinae }{ }^{\mathrm{a}} \text {, } \\
\text { Thoracic Erector Spinae, } \\
\text { Quadriceps Femoris } \\
\text { (bilaterally) }\end{array}$ & $\begin{array}{l}\text { EMG root mean } \\
\text { square } \\
\text { EMG integral }\end{array}$ & $\begin{array}{l}\text { Comparison } \\
\text { between without } \\
\text { and with the } \\
\text { exoskeleton }\end{array}$ & $\begin{array}{l}\text { Lumbar Erector Spinae: }-4.5 \% \text { (right) } \\
\text { Thoracic Erector Spinae: }-13 \% \text { (right), }-10 \% \text { (left) } \\
\text { Quadriceps Femoris: }+18.7 \% \text { (right), }+13.4 \% \text { (left) }\end{array}$ \\
\hline $\begin{array}{l}\text { HAL for care } \\
\text { support [18] }\end{array}$ & $\begin{array}{l}\text { Lumbar Erector Spinae }^{a} \text {, } \\
\text { Thoracic Erector Spinae, } \\
\text { Quadriceps Femoris } \\
\text { (bilaterally) }\end{array}$ & EMG integral & $\begin{array}{l}\text { Comparison } \\
\text { between without } \\
\text { and with the } \\
\text { exoskeleton }\end{array}$ & $\begin{array}{l}\text { Lumbar Erector Spinae: }-14 \% \text { (right) } \\
\text { Thoracic Erector Spinae: }-20.8 \% \text { (right), }-18.3 \% \\
\text { (left) } \\
\text { Quadriceps Femoris: }+6.5 \% \text { (right), }-11.3 \% \text { (left) }\end{array}$ \\
\hline PLAD-1 [19] & $\begin{array}{l}\text { Lumbar Erector Spinae, } \\
\text { Thoracic Erector Spinae, } \\
\text { External Obliques, } \\
\text { Rectus Abdominalis }\end{array}$ & EMG integral & $\begin{array}{l}\text { Comparison } \\
\text { between without } \\
\text { and with the } \\
\text { exoskeleton }\end{array}$ & $\begin{array}{l}\text { Lumbar Erector Spinae: }-23.9 \% \\
\text { Thoracic Erector Spinae: }-24.4 \% \\
\text { External Obliques: }-34.9 \%\end{array}$ \\
\hline PLAD-2 [20] & $\begin{array}{l}\text { Lumbar Erector Spinae, } \\
\text { Thoracic Erector Spinae }\end{array}$ & $\begin{array}{l}\text { EMG root mean } \\
\text { square }\end{array}$ & $\begin{array}{l}\text { Comparison of } \\
\text { metric increase } \\
\text { between without } \\
\text { and with the } \\
\text { exoskeleton }\end{array}$ & $\begin{array}{l}\text { Lumbar Erector Spinae: }+88 \% \text { (without } \\
\text { exoskeleton), }+26 \% \text { (with exoskeleton) } \\
\text { Thoracic Erector Spinae: }+104 \% \text { (without } \\
\text { exoskeleton), }+22 \% \text { (with exoskeleton) }\end{array}$ \\
\hline
\end{tabular}

${ }^{\mathrm{a}}$ Left Erector Spinae was not collected during HAL usage and results are not reported.

- Positive/negative power: it allows to evaluate if the mechanical power delivered to the human joints is well designed, in terms, for example, of being physiologically compatible. Positive mechanical power means that the assistive torque is fully transferred to the user, while negative power means that part of the power is exerted against the user.

\section{DISCUSSION}

The five evaluation categories proposed in this work are a first attempt to classify and summarize different evaluation metrics feasible for the assessment of a lumbar exoskeleton for industrial application. The proposed evaluation metrics aimed at gathering enough information, both objective and subjective, to make an effective assessment of the exoskeleton in assisting subjects during the load lifting activity. Well-controlled and structured laboratory experiments are the first and unavoidable step to evaluate the exoskeleton in this application. The use of a standard methodology is also useful to compare the features of different exoskeletons for worker assistance. However, as shown by selected studies, there are neither common methodologies nor uniform metrics to evaluate lumbar exoskeletons for lifting. Indeed, on one hand, as it regards the methods used to evaluate lumbar exoskeletons, there is no uniformity in the weight of the load lifted or the number and frequency of the lifting actions. Moreover, from the point of view of the used evaluation metrics, only electromyography seems to be the metric shared by all studies. However, monitored muscles, evaluation methods and performance metrics used change among studies, as shown in Table III. Therefore, even in the case of EMG analysis, the lack of standardization makes it difficult to compare the performance of different exoskeletons used as load lifting assist devices. Finally, it is worth to note that any of the selected studies used all the evaluation metrics proposed in this work.

\section{CONCLUSIONS}

Although industrial exoskeletons are one of the most emerging technologies to reduce the risk of developing WMSDs among manual handling workers, there is still the problem of benchmarking their efficacy. In this paper we proposed a list of possible metrics to perform the evaluation of an exoskeleton used to assist the load lifting task that can be comprehensive. The proposed work is not intended as an exhaustive list of methodology and metrics but aimed at fostering the discussion about the problem of lacking methodology for industrial exoskeletons evaluation.

\section{REFERENCES}

[1] A. Parent-Thirion, G. Vermeylen, G. van Houten, M. Wilkens, and A. Wilczynska, "Sixth European working conditions survey 
(EWCS)," Office for Official Publications of the European Communities, Luxembourg, LU, 2015.

[2] D. M. Frost, M. Abdoli-E, and J. M. Stevenson, "PLAD (personal lift assistive device) stiffness affects the lumbar flexion/extension moment and the posterior chain EMG during symmetrical lifting tasks," Journal of Electromyography and Kinesiology, vol. 19, no. 6, pp. e403-e412, 2009.

[3] D. Steffens, C. G. Maher, L. M. Pereira, and et al., "Prevention of low back pain: A systematic review and meta-analysis," JAMA Internal Medicine, vol. 176, no. 2, pp. 199-208, 2016.

[4] S. T. Al-Otaibi, "Prevention of occupational Back Pain," Journal of Family \& Community Medicine, vol. 22, no. 2, pp. 73-77, May 2015.

[5] B. D. Kaplansky, F. Y. Wei, and M. V. Reecer, "Prevention strategies for occupational low back pain," Clin Occup Environ Med, vol. 5, no. 3, pp. 529-44, v, 2006.

[6] A. Lahad, A. D. Malter, A. O. Berg, and R. A. Deyo, "The effectiveness of four interventions for the prevention of low back pain," Jama, vol. 272, no. 16, pp. 1286-1291, 1994.

[7] P. Jellema, M. W. van Tulder, M. N. van Poppel, A. L. Nachemson, and L. M. Bouter, "Lumbar supports for prevention and treatment of low back pain: a systematic review within the framework of the Cochrane Back Review Group," Spine, vol. 26, no. 4, pp. 377-386, 2001.

[8] V. M. Mattila, P. Sillanpää, T. Salo, H.-J. Laine, H. Mäenpää, and H. Pihlajamäki, "Orthotic insoles do not prevent physical stressinduced low back pain," European Spine Journal, vol. 20, no. 1, pp. 100-104, 2011.

[9] M. Frazer, R. Norman, R. Wells, and P. Neumann, "The effects of job rotation on the risk of reporting low back pain," Ergonomics, vol. 46, no. 9, pp. 904-919, 2003.

[10] A. D. Woolf and B. Pfleger, "Burden of major musculoskeletal conditions," World Health Organization, 2003.

[11] D. Hoy et al., "The global burden of low back pain: estimates from the Global Burden of Disease 2010 study," Annals of the rheumatic diseases, vol. 73, no. 6, pp. 968-974, 2014.

[12] M. P. de Looze, T. Bosch, F. Krause, K. S. Stadler, and L. W. O'Sullivan, "Exoskeletons for industrial application and their potential effects on physical work load," Ergonomics, vol. 59, no. 5, pp. 671-681, 2016.

[13] F. Lanotte, L. Grazi, B. Chen, N. Vitiello, and S. Crea, "A LowBack Exoskeleton can Reduce the Erector Spinae Muscles Activity During Freestyle Symmetrical Load Lifting Tasks," in 2018 7th IEEE International Conference on Biomedical Robotics and Biomechatronics (Biorob), 2018, pp. 701-706.

[14] B. Chen, L. Grazi, F. Lanotte, N. Vitiello, and S. Crea, "A RealTime Lift Detection Strategy for a Hip Exoskeleton," Frontiers in Neurorobotics, vol. 12, p. 17, 2018.

[15] B. Chen, L. Grazi, F. Lanotte, N. Vitiello, and S. Crea, "Lift Movement Detection with a QDA Classifier for an Active Hip Exoskeleton," in Wearable Robotics: Challenges and Trends, 2019, pp. 224-228.

[16] B. Chen, F. Lanotte, L. Grazi, N. Vitiello, and S. Crea, "Classification of Lifting Techniques for Application of A Robotic Hip Exoskeleton,” Sensors, vol. 19, no. 4, 2019.
[17] K. Huysamen, M. de Looze, T. Bosch, J. Ortiz, S. Toxiri, and L. W. O'Sullivan, "Assessment of an active industrial exoskeleton to aid dynamic lifting and lowering manual handling tasks," Applied Ergonomics, vol. 68, pp. 125-131, Apr. 2018.

[18] A. von Glinski et al., "Effectiveness of an on-body lifting aid

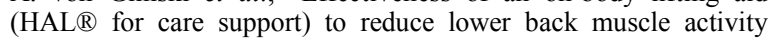
during repetitive lifting tasks," Journal of Clinical Neuroscience, Feb. 2019.

[19] M. Abdoli-E and J. M. Stevenson, "The effect of on-body lift assistive device on the lumbar 3D dynamic moments and EMG during asymmetric freestyle lifting," Clinical Biomechanics, vol. 23, no. 3, pp. 372-380, Mar. 2008.

[20] C. A. Lotz, M. J. Agnew, A. A. Godwin, and J. M. Stevenson, "The effect of an on-body personal lift assist device (PLAD) on fatigue during a repetitive lifting task," Journal of Electromyography and Kinesiology, vol. 19, no. 2, pp. 331-340, Apr. 2009.

[21] A. S. Koopman, I. Kingma, G. S. Faber, M. P. de Looze, and J. H. van Dieën, "Effects of a passive exoskeleton on the mechanical loading of the low back in static holding tasks," Journal of Biomechanics, vol. 83, pp. 97-103, Jan. 2019.

[22] L. Grazi, S. Crea, A. Parri, R. Molino Lova, S. Micera, and N. Vitiello, "Gastrocnemius Myoelectric Control of a Robotic Hip Exoskeleton Can Reduce the User's Lower-Limb Muscle Activities at Push Off," Frontiers in Neuroscience, vol. 12, p. 71, 2018.

[23] A. J. Young, H. Gannon, and D. P. Ferris, "A Biomechanical Comparison of Proportional Electromyography Control to Biological Torque Control Using a Powered Hip Exoskeleton," Frontiers in Bioengineering and Biotechnology, vol. 5, p. 37, 2017.

[24] T. Bosch, J. van Eck, K. Knitel, and M. de Looze, "The effects of a passive exoskeleton on muscle activity, discomfort and endurance time in forward bending work," Applied Ergonomics, vol. 54, pp. 212-217, 2016

[25] C. J. Payton and A. Burden, Biomechanical evaluation of movement in sport and exercise: the British Association of Sport and Exercise Sciences guide. Routledge, 2017.

[26] C. R. Guerrero, J. F. Marinero, J. P. Turiel, and P. R. Farina, "Using psychophysiological feedback to enhance physical human robot interaction in a cooperative scenario," in 2012 4th IEEE RAS \& EMBS International Conference on Biomedical Robotics and Biomechatronics (BioRob), 2012, pp. 1176-1181.

[27] N. d'Elia et al., "Physical human-robot interaction of an active pelvis orthosis: toward ergonomic assessment of wearable robots," Journal of NeuroEngineering and Rehabilitation, vol. 14, no. 1, p. 29, Apr. 2017.

[28] J. Brooke, "SUS: a" quick and dirty" usability scale in PW Jordan, B. Thomas, BA Weerdmeester, \& AL McClelland. Usability Evaluation in Industry," 1996.

[29] S. G. Hart and L. E. Staveland, "Development of NASA-TLX (Task Load Index): Results of empirical and theoretical research," in Advances in psychology, vol. 52, Elsevier, 1988, pp. 139-183.

[30] G. Borg, "Psychophysical scaling with applications in physical work and the perception of exertion," Scandinavian Journal of Work, Environment and Health, vol. 16, no. SUPPL. 1, pp. 55-58, 1990. 